Received: June 28, 2011

Accepted after revision: September 3, 2011 Published online: February 4, 2012

\title{
Hippocampal Drebrin Loss in Mild Cognitive Impairment
}

\author{
Scott E. Counts ${ }^{\mathrm{a}}$ Bin He $\mathrm{e}^{\mathrm{a}}$ Muhammad Nadeem ${ }^{\mathrm{a}}$ Joanne Wuu ${ }^{\mathrm{b}}$ \\ Stephen W. Scheff ${ }^{c, d}$ Elliott J. Mufson ${ }^{a}$ \\ a Department of Neurological Sciences, Rush University Medical Center, Chicago, Ill., b Department of Neurology, \\ University of Miami Miller School of Medicine, Miami, Fla., and 'Department of Anatomy and Neurobiology and \\ dSanders Brown Center on Aging, University of Kentucky, Lexington, Ky., USA
}

\section{Key Words}

Alzheimer's disease - Mild cognitive impairment • Synaptic protein - Synaptophysin · Synaptotagmin . Drebrin • Hippocampus

\begin{abstract}
Alterations in the relative abundance of synaptic proteins may contribute to hippocampal synaptic dysfunction in Alzheimer's disease (AD). The extent to which perturbations in synaptic protein expression occur during the earliest stages of cognitive decline remains unclear. We examined protein levels of presynaptic synaptophysin (SYP) and synaptotagmin (SYT), and postsynaptic drebrin (DRB), a marker for dendritic spine plasticity, in the hippocampus of people with an antemortem clinical diagnosis of no cognitive impairment $(\mathrm{NCl})$, mild cognitive impairment $(\mathrm{MCl})$ or mild/moderate $A D$. Although normalized SYP and SYT levels were preserved, DRB was reduced by approximately $40 \%$ in the hippocampus of $\mathrm{MCl}$ and $\mathrm{AD}$ compared to $\mathrm{NCl}$ subjects. This differential alteration of synaptic markers in $\mathrm{MCl}$ suggests a selective impairment in hippocampal postsynaptic dendritic plasticity in prodromal $A D$ that likely heralds the onset of memory impairment in symptomatic disease.
\end{abstract}

Copyright $\odot 2012$ S. Karger AG, Basel

\section{KARGER}

Fax +4161306 1234

E-Mail karger@karger.ch

www.karger.com
(C) 2012 S. Karger AG, Basel

Accessible online at: www.karger.com/ndd

\section{Introduction}

Hippocampal synapse loss is a prominent feature of Alzheimer's disease (AD) [1]. Decreases in synaptic density correlate better than amyloid plaques or neurofibrillary tangles with the degree of cognitive impairment in $A D$, suggesting that synaptic dysfunction contributes to the clinical presentation of the disease [2]. The efficacy of synaptic transmission depends upon the intricate coordination of multiple specialized proteins involved in synaptic vesicle trafficking (e.g. targeting and docking, membrane fusion/exocytosis and endocytosis) and pre- and postsynaptic structure and plasticity $[3,4]$. Therefore, perturbations in synaptic protein stoichiometry may play a role in synaptic dysfunction in AD. Several studies have shown that the expression levels of select synaptic proteins such as synaptophysin (SYP) [5], synaptotagmin (SYT) [6] and drebrin (DRB) [7] are decreased in the hippocampus in late-stage $\mathrm{AD}$, but whether similar alterations occur in people clinically diagnosed with mild cognitive impairment (MCI), a putative prodromal stage of AD [8], remains unclear. To address this question, we performed quantitative immunoblotting experiments to measure the levels of SYP (a presynaptic vesicle marker), SYT (a synaptic protein critical for $\mathrm{Ca}^{2+}$-dependent neurotransmitter 
Table 1. Clinical, demographic, and neuropathological case characteristics by diagnostic category

\begin{tabular}{|c|c|c|c|c|c|c|}
\hline & \multicolumn{4}{|l|}{ Clinical diagnosis } & $\mathrm{p}$ value & $\begin{array}{l}\text { Pairwise } \\
\text { comparison }\end{array}$ \\
\hline Number of males & $3(25 \%)$ & $4(44 \%)$ & $6(55 \%)$ & $13(40 \%)$ & $0.4^{\mathrm{c}}$ & - \\
\hline Years of education & $16.8 \pm 3.7(12-25)$ & $16.4 \pm 2.2(12-20)$ & $15.6 \pm 4.6(7-22)$ & $16.3 \pm 3.6(7-25)$ & $1.0^{\mathrm{b}}$ & - \\
\hline Number with ApoE $\varepsilon 4$ allele & 0 & $1(11 \%)$ & $5(45 \%)$ & $6(19 \%)$ & $0.0094^{c}$ & $\mathrm{NCI}<\mathrm{AD}$ \\
\hline \multicolumn{7}{|l|}{ Distribution of Braak scores } \\
\hline 0 & 0 & 0 & 0 & 0 & \multirow[t]{4}{*}{$<0.000^{\mathrm{b}}$} & \multirow[t]{4}{*}{$(\mathrm{NCI}, \mathrm{MCI})<\mathrm{AD}$} \\
\hline $\mathrm{I} / \mathrm{II}$ & 6 & 0 & 0 & 6 & & \\
\hline III/IV & 6 & 8 & 1 & 15 & & \\
\hline $\mathrm{V} / \mathrm{VI}$ & 0 & 1 & 10 & 11 & & \\
\hline \multicolumn{7}{|c|}{ NIA-Reagan diagnosis (likelihood of AD) } \\
\hline \multicolumn{7}{|l|}{ CERAD diagnosis } \\
\hline No AD & 6 & 1 & 0 & 7 & \multirow[t]{4}{*}{$0.0009^{\mathrm{b}}$} & \multirow[t]{4}{*}{$\mathrm{NCI}<\mathrm{AD}$} \\
\hline Possible & 0 & 1 & 0 & 1 & & \\
\hline Probable & 5 & 4 & 2 & 11 & & \\
\hline Definite & 1 & 3 & 9 & 13 & & \\
\hline
\end{tabular}

Figures are means \pm SD with ranges in parentheses unless indicated otherwise.

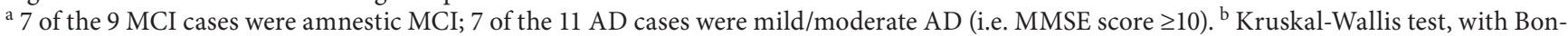
ferroni correction for multiple comparisons. ${ }^{c}$ Fisher's exact test, with Bonferroni correction for multiple comparisons.

release), and DRB (a postsynaptic dendritic spine marker) in postmortem hippocampus obtained from subjects classified antemortem as no cognitive impairment (NCI), $\mathrm{MCI}$ or mild/moderate $\mathrm{AD}$. These findings were correlated with performance on antemortem cognitive tests and postmortem neuropathologic variables.

\section{Materials and Methods}

\section{Subjects}

Hippocampi were obtained from 32 individuals enrolled in the Rush Alzheimer's Disease Center Religious Orders Study ( $\mathrm{n}=$ 16) [9] or the University of Kentucky Alzheimer's Disease Center $(\mathrm{n}=16)[10]$ who underwent annual detailed clinical evaluations and brain donations at death [9-11]. Hippocampal tissue containing the CA subfields and the dentate gyrus was harvested at the level of the lateral geniculate nucleus and frozen on dry ice. Cases were matched for age $(85.3 \pm 5.9$ years, mean $\pm \mathrm{SD})$, years of education $(16.3 \pm 3.6)$, postmortem interval $(4.5 \pm 2.3 \mathrm{~h})$ and gender (40\% males) and were categorized antemortem as NCI $[\mathrm{n}=10$; Mini Mental State Exam (MMSE) score = 28.1 \pm 1.9 ], MCI insufficient to meet criteria for dementia ( $\mathrm{n}=9$; MMSE score $=26.6 \pm 3.4)$, or mild/moderate AD $(n=11$; MMSE score $=$
$14.1 \pm 8.1$ ) (table 1) [9]. Seven of the 9 MCI cases were amnestic MCI based on impairments in episodic memory alone [8]. A neuropathologist classified each case based on CERAD (Consortium to Establish a Registry for Alzheimer's Disease) [12], Braak staging [13], and NIA-Reagan [14] diagnostic criteria (table 1).

\section{Quantitative Immunoblotting}

Immunoblotting was performed using a previously reported procedure [11]. Briefly, frozen hippocampi were homogenized with protease inhibitors and centrifuged at $1,000 \mathrm{rpm}$ for $10 \mathrm{~min}$ at $4^{\circ} \mathrm{C}$. S1 fraction proteins ( $25 \mu \mathrm{g} / \mathrm{sample}$ ) were separated by SDS-PAGE, transferred to Immobilon P membranes (Millipore, Mass., USA), blocked in Tris-buffered saline (pH 7.4)/0.1\% Tween-20/5\% milk, and incubated overnight at $4{ }^{\circ} \mathrm{C}$ with mouse anti-SYP (clone SY38; 1:1,000; MP Biomedicals, Calif., USA), mouse anti-SYT (clone 41; 1:2,000; BD Transduction Labs, Calif., USA), and mouse anti-DRB (clone M2F6; 1:2,000; MBL International, Mass., USA) in blocking buffer. Membranes were also incubated with mouse anti-tubulin (clone KMX-1; 1:50,000; Chemicon, Calif., USA) as the loading control; hence, for quantitative analysis, synaptic protein levels were normalized to tubulin levels in each sample [11]. Blots were incubated for $1 \mathrm{~h}$ with horseradish peroxidase-conjugated goat anti-mouse IgG secondary antibody (1:8,000; Pierce, Ill., USA) and reactivity was quantified using Kodak $1 \mathrm{D}$ image analysis software (Perkin-Elmer, Mass., USA). Each sample was analyzed on three different Western blots in independent experiments. 
Table 2. Summary of hippocampal DRB, SYP, and SYT levels by diagnosis category

\begin{tabular}{|c|c|c|c|c|c|c|}
\hline & \multicolumn{4}{|c|}{ Clinical diagnosis (mean $\pm S D)$} & \multirow{2}{*}{$\begin{array}{l}\mathrm{p} \\
\text { value }^{\mathrm{a}}\end{array}$} & \multirow{2}{*}{$\begin{array}{l}\text { Pairwise } \\
\text { comparison }\end{array}$} \\
\hline & $\mathrm{NCI}(\mathrm{n}=12)$ & $\operatorname{MCI}(n=9)$ & $\operatorname{AD}(n=11)$ & total $(n=32)$ & & \\
\hline DRB & $0.43 \pm 0.20(0.18-0.84)$ & $0.24 \pm 0.13(0.06-0.49)$ & $0.25 \pm 0.13(0.07-0.45)$ & $0.32 \pm 0.18(0.06-0.84)$ & 0.045 & $\mathrm{NCI}>(\mathrm{MCI}, \mathrm{AD})$ \\
\hline SYP & $3.64 \pm 1.33(1.41-6.38)$ & $3.32 \pm 1.55(0.92-5.69)$ & $3.80 \pm 1.89(1.51-6.86)$ & $3.60 \pm 1.56(0.92-6.86)$ & 0.84 & - \\
\hline SYT & $0.88 \pm 0.39(0.35-1.62)$ & $0.91 \pm 0.45(0.34-1.64)$ & $0.94 \pm 0.61(0.41-2.32)$ & $0.91 \pm 0.47(0.34-2.32)$ & 0.97 & - \\
\hline
\end{tabular}

Figures in parentheses indicate ranges.

a Kruskal-Wallis test, with Bonferroni correction for multiple comparisons.

\section{Statistical Analysis}

Synaptic protein levels were compared among groups using Kruskal-Wallis testing with Bonferroni correction for multiple comparisons. Relationships between synaptic protein levels and clinical and pathologic variables were assessed by Spearman correlation. The level for statistical significance was set at 0.05 (twotailed).

\section{Results}

Hippocampal Synaptic Protein Levels in MCI and AD

There were no significant differences in mean hippocampal SYP or SYT levels across the clinical groups (fig. 1; table 2). By contrast, mean DRB protein levels were decreased by approximately $40-45 \%$ in MCI and AD compared to NCI (fig. 1; table 2). SYP, SYT, or DRB levels were not correlated with either antemortem performance on the MMSE, episodic memory tests referable to hippocampal function (e.g. logical memory immediate recall) [9], or postmortem Braak, CERAD, or NIA-Reagan neuropathological scores.

\section{Discussion}

Synapse loss in the hippocampus correlates with the severity of clinical symptoms in AD [1], yet the pathogenic mechanisms underlying synaptic dysfunction remain unclear. Previous reports have demonstrated preferential reductions in specific synaptic proteins in latestage AD, including SYP [5], SYT [6], and DRB [7]. The present quantitative immunoblotting study revealed that DRB levels were also selectively reduced in MCI and early-stage AD, whereas SYP and SYT levels were stable across diagnostic groups, indicating that alterations in the expression of synaptic regulatory elements occur early in the disease process. These findings are similar to

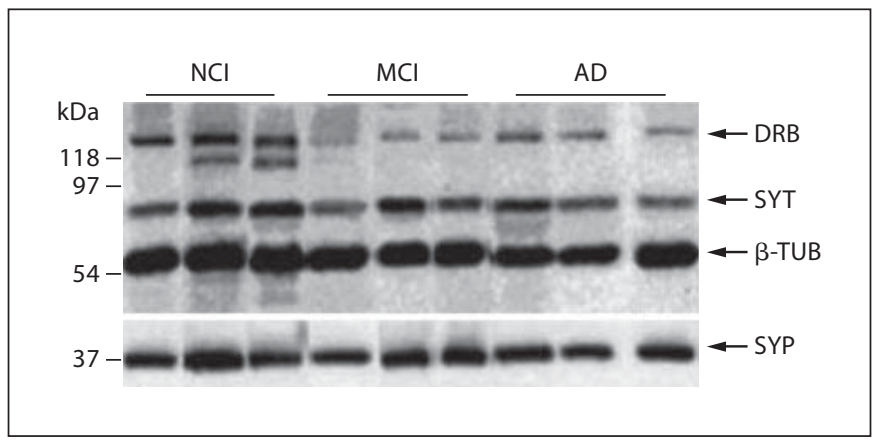

Fig. 1. Representative immunoblot showing hippocampal DRB, SYT, SYP, and $\beta$-tubulin ( $\beta$-TUB) immunoreactivity in samples from NCI, MCI, and AD subjects.

those found in the temporal neocortex, where levels of $\mathrm{DRB}$ were reduced in MCI, SYP was decreased only in late-stage $\mathrm{AD}$, and $\mathrm{SYT}$ was stable during the progression of $\mathrm{AD}$ [11].

Functionally, SYP is a key player in membrane trafficking events preceding exocytosis, whereas SYT is a $\mathrm{Ca}^{2+}$ microsensor that modulates activity-dependent exocytosis [15]. Hence, hippocampal presynaptic efficacy may be relatively preserved in the prodromal stages of AD. Alternatively, the stability of these presynaptic markers may reflect the ability of the hippocampus to display biochemical plasticity in MCI [16].

$\mathrm{DRB}$, on the other hand, is an F-actin-binding protein localized to postsynaptic dendritic spines at excitatory synapses [17], where it plays a role in synaptic plasticity by regulating spine morphogenesis [17], organizing postsynaptic densities [18], and targeting receptors [19]. Intriguingly, DRB-dependent clustering of actin was shown to be critical for the postsynaptic targeting of the protein PSD-95, which is also involved in excitatory postsynaptic plasticity [18] and reduced in the MCI hippocampus [10]. 
The lack of association between DRB levels alone and cognitive performance may signify that alterations of multiple synaptic markers are required to precipitate clinically relevant disturbances in cognition function. Taken together, these findings suggest that the hippocampus displays postsynaptic pathology and decreased synaptic plasticity in the prefatory stages of $\mathrm{AD}$, which over time contributes to the onset of frank dementia.

\section{Acknowledgements}

The study was supported by: NIH AG14449, AG10161, AG10688 and AG09466 (to E.J.M.), and AG03500 (to S.E.C.).

\section{References}

1 Scheff SW, Price DA, Schmitt FA, Mufson EJ: Hippocampal synaptic loss in early Alzheimer's disease and mild cognitive impairment. Neurobiol Aging 2006;27:1372-1384.

$\checkmark 2$ Terry RD, Masliah E, Salmon DP, Butters N, DeTeresa R, Hill R, Hansen LA, Katzman R: Physical basis of cognitive alterations in Alzheimer's disease: synapse loss is the major correlate of cognitive impairment. Ann Neurol 1991;30:572-580.

3 Murthy VN, De Camilli P: Cell biology of the presynaptic terminal. Annu Rev Neurosci 2003;26:701-728.

4 Kennedy MB, Beale HC, Carlisle HJ, Washburn LR: Integration of biochemical signalling in spines. Nat Rev Neurosci 2005;6:423434.

5 Honer WG, Dickson DW, Gleeson J, Davies P: Regional synaptic pathology in Alzheimer's disease. Neurobiol Aging 1992;13:375382.

6 Davidsson P, Blennow K: Neurochemical dissection of synaptic pathology in Alzheimer's disease. Int Psychogeriatr 1998;10:1123.

7 Harigaya Y, Shoji M, Shirao T, Hirai S: Disappearance of actin-binding protein, drebrin, from hippocampal synapses in Alzheimer's disease. J Neurosci Res 1996;43:87-92.
8 Petersen RC: Mild cognitive impairment as a diagnostic entity. J Intern Med 2004;256: 183-194.

-9 Bennett DA, Wilson RS, Schneider JA, Evans DA, Beckett LA, Aggarwal NT, Barnes LL, Fox JH, Bach J: Natural history of mild cognitive impairment in older persons. Neurology 2002;59:198-205.

10 Sultana R, Banks WA, Butterfield DA: Decreased levels of PSD95 and two associated proteins and increased levels of $\mathrm{BCl} 2$ and caspase 3 in hippocampus from subjects with amnestic mild cognitive impairment: insights into their potential roles for loss of synapses and memory, accumulation of Abeta, and neurodegeneration in a prodromal stage of Alzheimer's disease. J Neurosci Res 2010;88:469-477.

11 Counts SE, Nadeem M, Lad SP, Wuu J, Mufson EJ: Differential expression of synaptic proteins in the frontal and temporal cortex of elderly subjects with mild cognitive impairment. J Neuropathol Exp Neurol 2006; 65:592-601.

-12 Mirra SS, Heyman A, McKeel D, Sumi SM, Crain BJ, Brownlee LM, Vogel FS, Hughes JP, van Belle G, Berg L: The Consortium to Establish a Registry for Alzheimer's Disease (CERAD). 2. Standardization of the neuropathologic assessment of Alzheimer's disease. Neurology 1991;41:479-486.
13 Braak H, Braak E: Neuropathological stageing of Alzheimer-related changes. Acta Neuropathol 1991;82:239-259.

14 The National Institute on Aging: Consensus recommendations for the postmortem diagnosis of Alzheimer's disease. Neurobiol Aging 1997;18:S1-S2.

15 Sudhof TC: The synaptic vesicle cycle. Annu Rev Neurosci 2004;27:509-547.

16 DeKosky ST, Ikonomovic MD, Styren SD, Beckett L, Wisniewski S, Bennett DA, Cochran EJ, Kordower JH, Mufson EJ: Upregulation of choline acetyltransferase activity in hippocampus and frontal cortex of elderly subjects with mild cognitive impairment. Ann Neurol 2002;51:145-155.

17 Hayashi K, Ishikawa R, Ye LH, He XL, Takata K, Kohama K, Shirao T: Modulatory role of drebrin on the cytoskeleton within dendritic spines in the rat cerebral cortex. J Neurosci 1996;16:7161-7170.

18 Takahashi H, Sekino Y, Tanaka S, Mizui T, Kishi S, Shirao T: Drebrin-dependent actin clustering in dendritic filopodia governs synaptic targeting of postsynaptic density-95 and dendritic spine morphogenesis. J Neurosci 2003;23:6586-6595.

19 Takahashi H, Mizui T, Shirao T: Down-regulation of drebrin A expression suppresses synaptic targeting of NMDA receptors in developing hippocampal neurones. J Neurochem 2006;97(suppl 1):110-115. 